\title{
Multisource Information Risk Evaluation Technology of Mine Water Inrush Based on VWM: A Case Study of Weng'an Coal Mine
}

\author{
Bo Li $\mathbb{D}^{1,2}{ }^{1,2}$ Tao Li, ${ }^{3}$ Wenping Zhang, ${ }^{2}$ Zijie Liu, ${ }^{2}$ and Lei Yang ${ }^{4}$ \\ ${ }^{1}$ Key Laboratory of Karst Georesources and Environment, Ministry of Education, Guizhou University, Guiyang 550025, China \\ ${ }^{2}$ College of Resource and Environmental Engineering, Guizhou University, Guiyang 550025, China \\ ${ }^{3}$ School of Mines and Civil Engineering, Liupanshui Normal University, Liupanshui 553004, China \\ ${ }^{4}$ Guizhou Zhong Gui Environmental Technology Co. Ltd., Guiyang 550025, China \\ Correspondence should be addressed to Bo Li; libo1512@163.com
}

Received 29 May 2020; Revised 26 April 2021; Accepted 9 May 2021; Published 24 May 2021

Academic Editor: Giovanni Mongelli

Copyright (c) 2021 Bo Li et al. This is an open access article distributed under the Creative Commons Attribution License, which permits unrestricted use, distribution, and reproduction in any medium, provided the original work is properly cited.

\begin{abstract}
The use of multisource information fusion technology to predict the risk of water inrush from coal floor is a research hotspot in recent years, but the current evaluation method is mainly based on a constant weight evaluation model. Using constant weights to reflect the control effect of changing factor state values on water inrush evaluation has obvious limitations, and it is unable to describe the control effect of the hydrogeological condition mutation on the water inrush from the floor. In order to solve the above problems, this manuscript introduces the idea of variable weight into the field of water inrush evaluation, expounds on the significance of variable weight theory for water inrush evaluation, analyzes the characteristics of mine water inrush variable weight evaluation, and, on this basis, further combines GIS-based multisource information fusion technology and typical engineering case to compare with the evaluation effect map, evaluation unit, and comprehensive evaluation values. The differences between the variable weight model (VWM) and the constant weight model (CWM) are analyzed, which proves that the evaluation process of the variable weight evaluation model is more reasonable and can effectively improve the evaluation accuracy.
\end{abstract}

\section{Introduction}

Mine water risk has always been one of the important factors restricting coal mining in China, and it is of great application value to carry out research on mine water inrush risk prediction technology [1-5]. In China, the forecast of coal floor water inrush has been studied for more than 40 years. In the early 1960s, according to a large number of mine water inrush data, the empirical formula of the water inrush coefficient method (WICM) for predicting water inrush was summarized, and it has been used until now [6-8]. However, there are many factors influencing water inrush disaster [9-12]. The WICM only considers the water pressure and aquiclude thickness. It does not fully reflect the nonlinear dynamic phenomenon controlled by multifactors. Based on the above reasons, from the beginning of the 20th century to the present, some scholars have adopted the geographic information systems (GIS) with linear or nonlinear integration technology and proposed the water inrush evaluation method based on multisource information fusion technology. For example, Dai et al. analyzed the water inrush risk of the 11th coal seam in Hancheng mining area using GIS and analytic hierarchy process (AHP) [13]. Wu et al. proposed a karst water inrush water risk prediction method based on GIS and artificial neural network (ANN) coupling technology [14]. Hu et al. obtained the weights of the evaluation factors through AHP and the entropy weight method and further determined water inrush risk zonation by using GIS technology [15]. Similar studies also include Liu et al. [16], Chen et al. [17], and Ruan et al. [18]. This type of method can better solve the problem of water inrush prediction [19]. However, in the process of applying multisource information fusion technology to predict water inrush, the currently widely used evaluation model is the weighted average model: $M\left(x_{1}, x_{2}, \cdots, x_{m}\right)=\sum_{i=1}^{m} w_{i} x_{i}$, where $x_{i}$ is the state value of factors influencing water inrush and $w_{i} \in[0,1]$ is the weight of the influencing factor and needs to satisfy $\sum_{i=1}^{m} w_{i}=1[20,21]$. In this model, regardless of how the 
state vector $X=\left(x_{1}, x_{2}, \cdots, x_{m}\right)$ of each factor changes, the weight vector $W=\left(w_{1}, w_{2}, \cdots, w_{m}\right)$ of the factor always remains unchanged. This method reflects the relative importance of individual factors in the overall evaluation system to a certain extent and has certain scientific nature and applicability. However, under certain weight vector levels, the water inrush evaluation result is not only related to each basic importance of influencing factors but also related to the magnitude of the factor state value and the combination relationship of the state value of each factor; that is, the state vector $X=\left(x_{1}, x_{2}, \cdots, x_{m}\right)$ of the constant coping factor of the weight vector $W=\left(w_{1}, w_{2}, \cdots, w_{m}\right)$ has a certain limitation. The CWM ignores the influence of the internal differences of the factor state value on the evaluation process and is unable to describe the control effect of the change of state value caused by the change of hydrogeological conditions. The more factors involved in the evaluation, the more average the weights, the greater the probability of making a wrong judgment.

In order to solve the above technical defect, this paper introduces the variable weight idea into the process of water inrush risk evaluation. The VWM can realize the change of factor weight value with the change of its state value, which can more accurately reflect the influence effect of water inrush by a sudden change of hydrogeological condition. The evaluation process is more consistent with the law of occurrence of water inrush and has a positive effect on improving the accuracy of water inrush evaluation. The method proposed in this paper can provide a reference for the risk evaluation of water inrush from the coal floor in areas with similar geological conditions in the world.

\section{Overview of the Research Area}

2.1. Physical Geography. Weng'an Coal Mine is located in Weng'an county in Guizhou province within the geographic coordinate of $107^{\circ} 28^{\prime} 30^{\prime \prime} \sim 107^{\circ} 32^{\prime} 30^{\prime \prime}$ (east longitude) and $26^{\circ} 57^{\prime} 57^{\prime \prime} \sim 27^{\circ} 03^{\prime} 15^{\prime \prime}$ (north latitude); the geography location is shown in Figure 1. The topography of the mining area is generally high in the south and low in the north. The eastern and western regions are the ridges with a north-south direction, while the central region is a valley, with a long strip of about $20 \mathrm{~km}$ length and $3-5 \mathrm{~km}$ width.

2.2. Meteorological and Hydrological. The climate type of the mining area belongs to the subtropical humid monsoon climate, and the rainy season is concentrated from April to September, with the annual rainfall reaching $1148.2 \mathrm{~mm}$. The rainfall in the rainy season accounts for more than $70 \%$ of the total annual rainfall. The surface water system of the mining area belongs to the tributaries of Baishui river tributary, Yangtze river basin. And the Baishui river runs through the whole area, and it is the main river in the region. Along both sides of the Baishui river develops a seasonal stream with short flow, small water, and dry season.

2.3. Geological Conditions. According to the borehole data, the exposed strata from old to new are the Middle Permian System Maokou Formation $\left(\mathrm{P}_{2} \mathrm{~m}\right)$, Upper Permian System
Emeishan Basalt Formation $\left(\mathrm{P}_{3} \beta\right)$, the Upper Permian System Wujiaping Formation $\left(\mathrm{P}_{3} \mathrm{~W}\right)$, the Upper Permian System Changxing Formation $\left(\mathrm{P}_{3} \mathrm{C}\right)$, the Lower Triassic System Yelang Formation $\left(\mathrm{T}_{1} \mathrm{y}\right)$, and the Quaternary $(\mathrm{Q})$. The mine is located on the wings of the Yangzi washing horse syncline of quasistation, and the oblique axis is distributed in the north-south direction. The dip angle of the two wings is $10-37^{\circ}$, which is basically symmetrical. Three faults are developed in the mining area, one fault is nearly northeastward and extends longer, and the other two faults are near east-west and small in scale. The coal-bearing strata are Permian Wujiaping Formation $\left(\mathrm{P}_{3} \mathrm{w}\right)$. It is a set of gray, light gray thin-layered carbon mudstone and silty mudstone with argillaceous siltstone, containing four layers of coal; only Dth coal seam can be mined. It is the target coal seam for this evaluation (Figure 2).

2.4. Hydrogeological Conditions. According to the geological borehole data of the mining area, the lithology of Middle Permian Maokou Formation $\left(\mathrm{P}_{2} \mathrm{~m}\right)$ is gray to grayish thick layer and the massive micritic limestone powder, containing a small amount of irregular chert nodule, and its thickness is greater than $60 \mathrm{~m}$. According to the results of a hydrogeological survey, the karst fissure of this aquifer is strongly developed and belongs to a water-rich confined aquifer. There is a wide distribution range between limestone and main coal seam of Maokou Formation, but the thickness of which is not uniform. As an aquiclude, basalt can generally function as a water barrier under natural conditions. However, under the coupling of mining stress and high-pressure water, water inrush is easy to form in the weak area of the aquiclude.

\section{The Thematic Maps of the Factors}

At present, there has been a lot of research in the field of water inrush control factors, such as Wu et al. [22], Li et al. [23], and Zeng [24]. Based on the previous research data, according to the hydrogeological conditions and the current geological exploration degree, ignoring the factors that have little effect on the water inrush process, the following six key control factors were selected as the control factors for the water inrush from the floor in Weng'an Coal Mine: (1) Equivalent thickness of effective aquiclude (ETEA): the effective aquiclude is equal to the total thickness of the aquiclude minus the depth of the failure zone of the mine, and the equivalent thickness is the thickness that converts the effective thickness of different lithologies into the same standard lithology. (2) Thickness of brittle rock under failure zone of the mine (TBRFZM): there are brittle rocks such as sandstone and limestone in the aquifuge, which have strong compressive capacity for preventing water inrush. Therefore, the total thickness of brittle rock after the failure zone is reduced as one of the evaluation indicators of water inrush. (3) Distribution of faults and folds (DFF): the rock mass integrity of the aquiclude in the fault and fold distribution is generally poor, and the fractures formed by these geological structures can easily become the passage of groundwater into the mine. (4) Rock quality designation of aquiclude (RQDA): the rock quality designation of aquiclude refers to the ratio of the core 


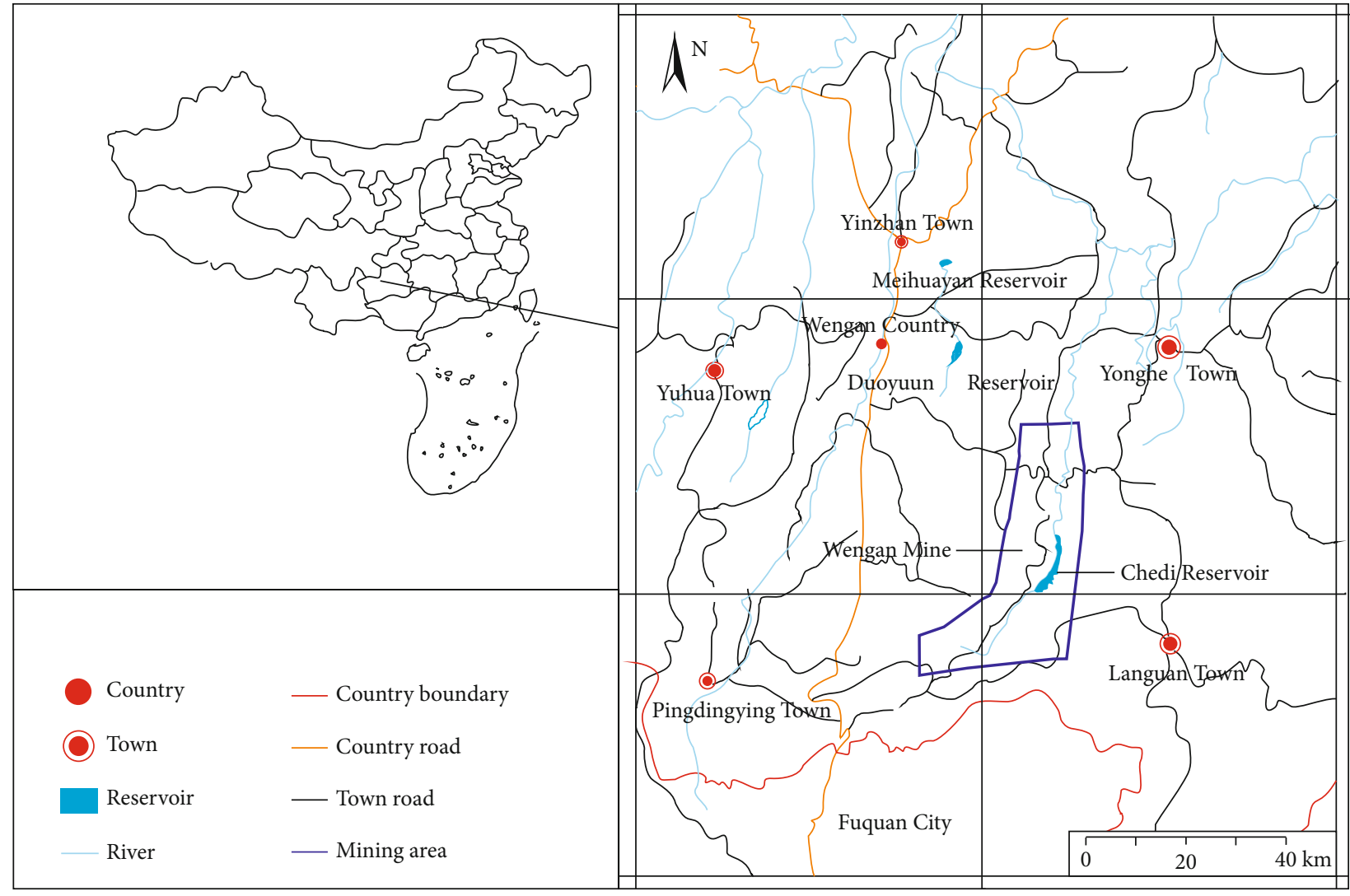

FIGURE 1: Geography location.

length obtained by drilling to the corresponding actual drilling footage, which can reflect the degree of fracture development of the aquiclude. (5) Water abundance of limestone aquifer (WALA): the water abundance of the aquifer is the water-bearing capacity of the aquifer, which determines the amount of water inrush. (6) Water pressure of limestone aquifer (WPLA): high water pressure is the driving factor for the groundwater suddenly flooded into the mine, and it is a prerequisite for the formation of water inrush. The data of various influencing factors of water inrush from the D coal floor of Weng'an Coal Mine were collected and organized, and the original data were processed and interpolated to generate thematic maps of various control factors and establish the factor database. For the method of data processing and interpolation calculation, please refer to $\mathrm{Wu}$ et al. $[22,25]$. Because of the limited space, only the WPLA thematic map is taken as an example in the text, as shown in Figure 3; the other thematic maps (Figures S1-S5) are in Supplementary Materials.

The purpose of normalizing is to eliminate the influence of different dimensions on the evaluation results, so that it is statistically significant and comparable $[19,26]$. The normalization formula used is as follows:

$$
N_{i}=\eta+\frac{(u-\eta) \times\left(x_{i}-\min \left(x_{i}\right)\right)}{\max \left(x_{i}\right)-\min \left(x_{i}\right)} .
$$

$N_{i}$ is the normalized value, $\min \left(x_{i}\right)$ is the minimum state value, $\max \left(x_{i}\right)$ is the maximum state value, $u$ is the upper limit of the normalized range, and $\eta$ is the lower limit of the normalized range; in the normalization process, $u=1, \eta=0$.

Among the identified influencing factors, the WALA, RQDA, WPLA, and DFF are positively related to the water inrush risk, which means that the larger the quantified value of these factors, the more likely it is to produce a sudden change. The ETEA and DFF are negatively correlated. In this paper, the negative correlation data is normalized by $\left(1-N_{i}\right)$.

\section{Risk Evaluation of Water Inrush Based on VWM}

4.1. Overview of Variable Weight Theory. The variable weight theory is a new comprehensive decision-making method first proposed in the book Fuzzy Sets and Projectable Random Sets in the 1980s. Subsequently, Li [27, 28], Liu [29], Li and Li [30], Cai and $\mathrm{Li}$ [31], and other mathematicians continued their research on this theory and gradually formed a relatively complete theory. The VWM can realize the weight changes with the change of the factor state value, so that the influence of each factor on the evaluation system under different combination states is better reflected by the change of the weight, which makes it a more scientific weight. The relevant content of the variable weight theory can be found in references, which will not be explained in the paper. 


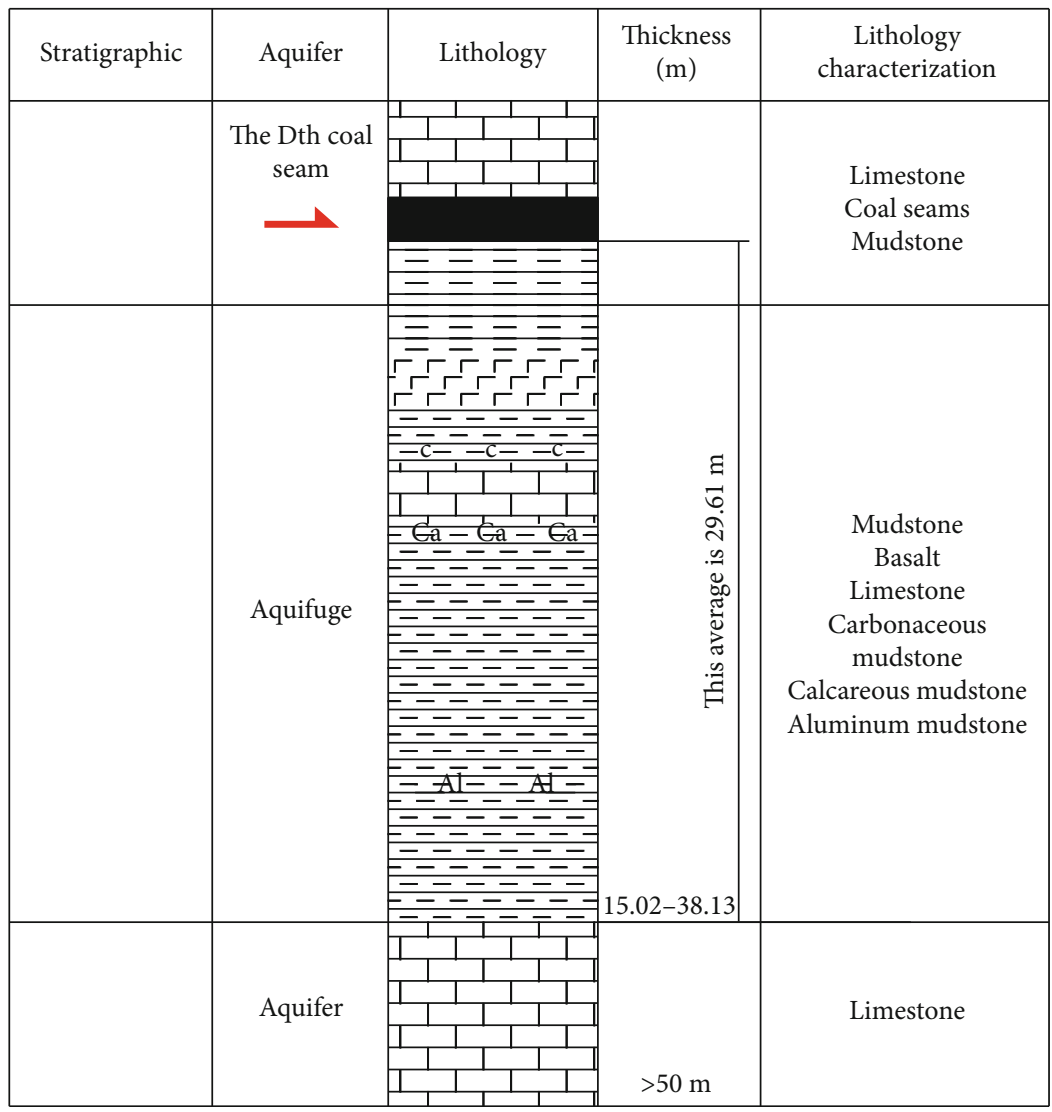

Figure 2: Structural relationship between coal seam and aquifer.

\subsection{Evaluation Steps}

(1) Determine the water inrush risk evaluation factors of the coal seam floor and produce thematic maps

(2) Use the analytic hierarchy process (or other weight calculation methods) to determine the constant weight of each factor

(3) Formulate the weight adjustment plan and construct the state variable weight vector formula according to the plan (formula (3)). It should be noted that researchers can construct the corresponding state variable weight vector according to the actual geological conditions of the coal mine

(4) On the basis of determining the state variable weight vector formula, according to formula (2), establish the water inrush risk assessment model and use Matlab software to compile the solution program

(5) According to industry specifications and the geological conditions of the research area, determine the variable weight interval thresholds of different factors. Through continuous debugging of the model, determine the optimal weight adjustment parameter values

(6) On the basis of determining the model parameters, the variable weight of different evaluation units of each factor is calculated. According to the state value and variable weight of the factors in different evaluation units, the comprehensive evaluation value of all evaluation units is obtained

(7) Identify the accuracy of the water inrush risk assessment results

4.3. Evaluation Idea and Model. In the process of GIS-based floor water inrush risk evaluation, the evaluation area will be divided into many evaluation units, each evaluation unit contains all the control factors, and the status value of each control factor is different in different evaluation units. Especially when the status value of a factor in the evaluation unit is very high or very low, it often means that this factor has a stronger control effect on water inrush. In order to avoid the very high or very low state value of a factor in the evaluation unit being neutralized by other factors, the model can significantly increase the weight value of this type of factor. At the same time, the high state value will lead to a significant increase in risk, but the state value is very low and does not necessarily significantly reduce the risk; therefore, the weight of the high state value is increased by a larger amount in the model. It should be noted that the weight of each factor is a secondary adjustment based on its constant weight, so the adjusted weight value does not change the relative importance relationship between each factor. According to the ideas, a risk evaluation model for water inrush based on variable weight theory is constructed [22], as follows: 


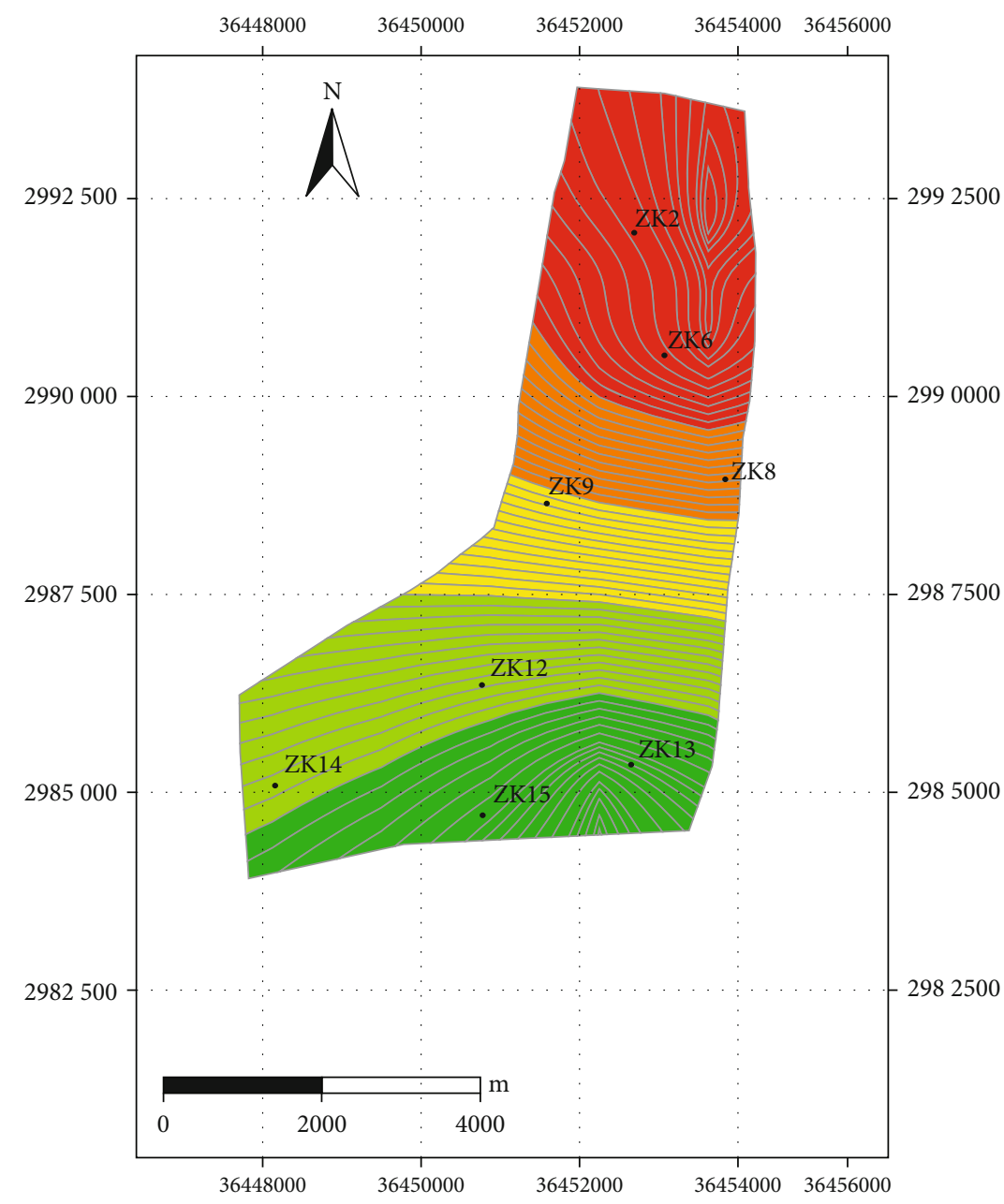

WPLA (MPa)

- Drill hole

$3.627845-3.862500$

$3.862501-4.162500$

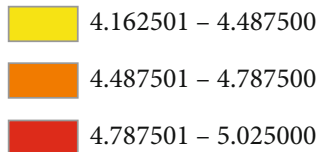

$4.787501-5.025000$

FIgURE 3: The thematic map of WPLA.

$$
\begin{aligned}
\mathrm{RI}= & \sum_{i=1}^{m} w_{i} \cdot f_{i}(x, y)=\sum_{i=1}^{m} \frac{w_{i}^{(0)} V_{i}(X)}{\sum_{j=1}^{m} w_{j}^{(0)} V_{j}(X)} f_{i}(x, y) \\
= & \frac{w_{1}^{(0)} V_{1}(X)}{\sum_{j=1}^{m} w_{j}^{(0)} V_{j}(X)} f_{1}(x, y)+\frac{w_{2}^{(0)} V_{2}(X)}{\sum_{j=1}^{m} w_{j}^{(0)} V_{j}(X)} f_{2}(x, y) \\
& +\cdots+\frac{w_{m}^{(0)} V_{m}(X)}{\sum_{j=1}^{m} w_{j}^{(0)} V_{j}(X)} f_{m}(x, y),
\end{aligned}
$$

where $\mathrm{RI}$ is the risk index, $w_{i}$ is the variable weight vector, $f_{i}(x, y)$ is the state value, $x$ and $y$ are the coordinates, $w^{(0)}$ is the constant weight vector, $m$ is the number of factors, and $V(X)$ is the state variable weight vector, expressed as follows:

$$
V_{j}(x)= \begin{cases}e^{a_{1}\left(b_{j_{1}}-x\right)}+p-1, & x \in\left[0, b_{j 1}\right), \\ c, & x \in\left[b_{j 1}, b_{j 2}\right), \\ e^{a_{2}\left(x-b_{j_{2}}\right)}+p-1, & x \in\left[b_{j 2}, b_{j 3}\right), \\ e^{a_{3}\left(x-b_{j_{3}}\right)}+e^{a_{2}\left(b_{j_{3}}-b_{j 2}\right)}+p-2, & x \in\left[b_{j 3}, 1\right],\end{cases}
$$

where $a_{1}, a_{2}, a_{3}$, and $p$ are adjustment weight parameters; in this evaluation, $a_{1}=1.46, a_{2}=0.9, a_{3}=0.819$, and $p=$ 1.635. $b_{\mathrm{j} 1}, b_{\mathrm{j} 2}$, and $b_{\mathrm{j} 3}$ are threshold values of the $j$ th factor variable weight interval.

The different status values of the factors have different control effects on water inrush, and the variable weight 
TABLE 1: Variable weight interval of main control factors.

\begin{tabular}{|c|c|c|c|c|}
\hline \multirow{2}{*}{ Main controlling factors } & \multicolumn{4}{|c|}{ Variable weight interval } \\
\hline & {$\left[0, b_{j 1}\right]$} & {$\left[b_{j 3}, 1\right]$} & {$\left[b_{j 2}, b_{j 3}\right]$} & {$\left[b_{j 3}, 1\right]$} \\
\hline WPLA & $0 \leq x<0.288$ & $0.288 \leq x<0.561$ & $0.561 \leq x<0.818$ & $0.818 \leq x \leq 1$ \\
\hline ETEA & $0 \leq x<0.196$ & $0.196 \leq x<0.537$ & $0.537 \leq x<0.728$ & $0.728 \leq x \leq 1$ \\
\hline TBRFZM & $0 \leq x<0.228$ & $0.228 \leq x<0.506$ & $0.506 \leq x<0.825$ & $0.825 \leq x \leq 1$ \\
\hline WALA & $0 \leq x<0.288$ & $0.288 \leq x<0.561$ & $0.561 \leq x<0.818$ & $0.818 \leq x \leq 1$ \\
\hline DFF & & $0 \leq x<0.500$ & $0.500 \leq x<0.800$ & $0.800 \leq x \leq 1$ \\
\hline RQDA & $0 \leq x<0.183$ & $0.183 \leq x<0.567$ & $0.567 \leq x<0.800$ & $0.800 \leq x \leq 1$ \\
\hline
\end{tabular}

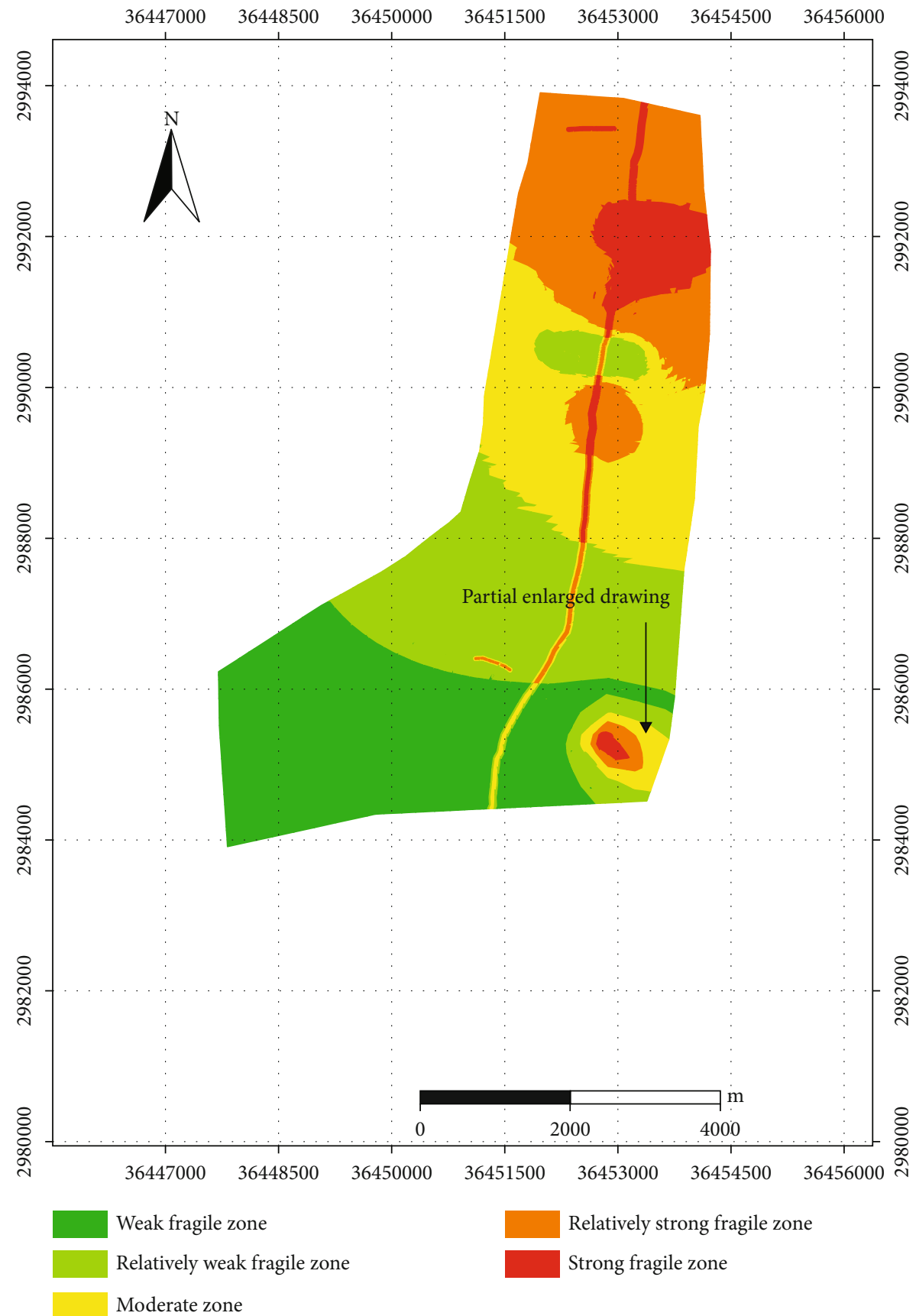

FIgURe 4: Risk partition map based on VWM. 


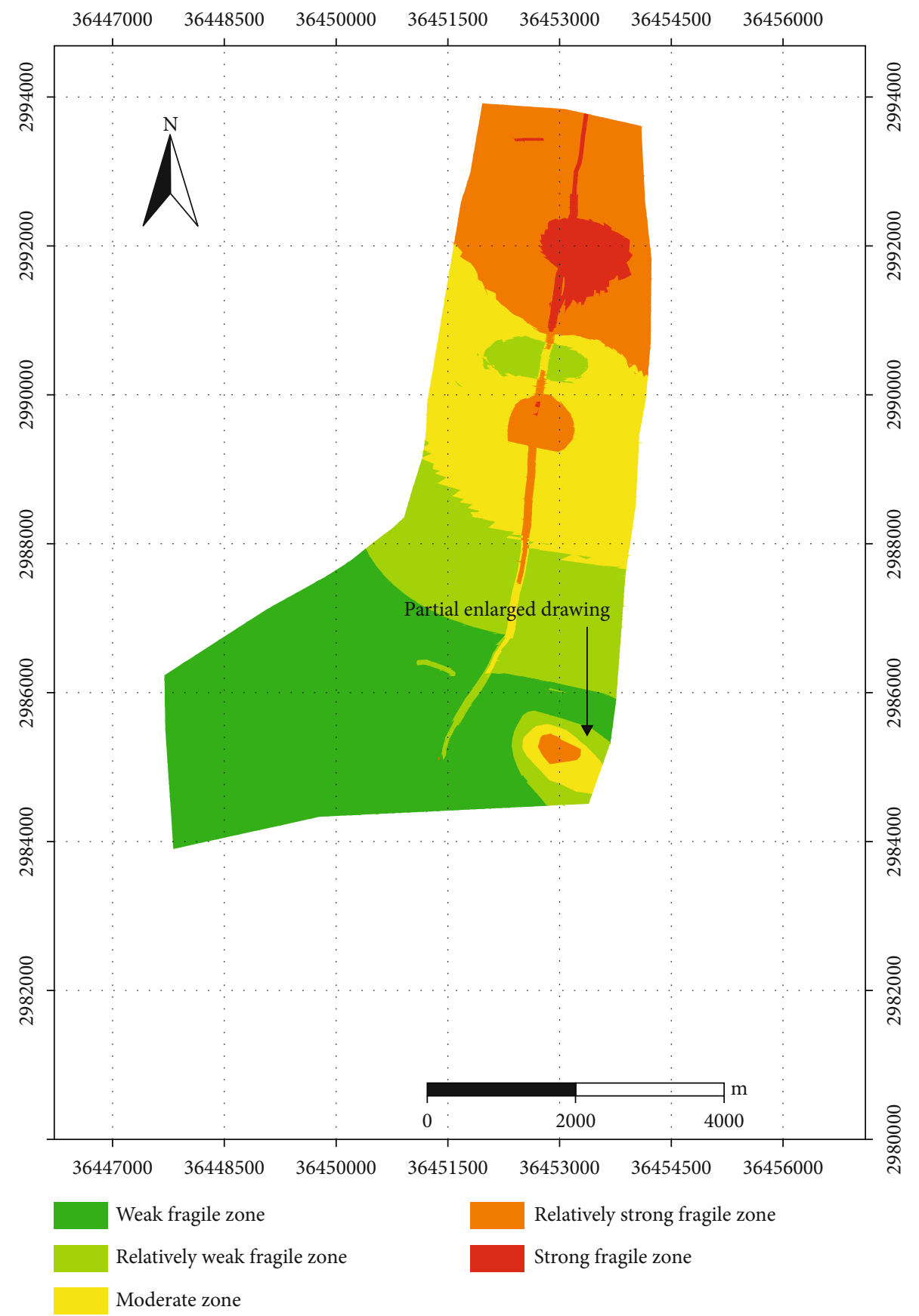

FIgURE 5: Risk partition map based on CWM.

interval threshold determines the degree of weight adjustment of different types of state values of each factor. In $\left[b_{j 3}, 1\right]$, the weight increases as the state value increases; in $\left[b_{j 2}, b_{j 3}\right)$, the weight increases as the state value increases, but the magnitude of the increase is smaller than the $\left[b_{j 3}, 1\right]$ interval. In $\left[b_{j 1}, b_{j 2}\right)$, the weight is neither increased nor decreased; at $\left[0, b_{j 1}\right)$, the weight increases as the state value decreases. In this paper, according to the characteristics of the difference in the spatial distribution of the state values of the factors, the clustering analysis method is used to determine the variable weight interval of each main control factor, as shown in Table 1.
4.4. Water Inrush Risk Evaluation. Before multifactor fusion analysis, firstly, the composite superposition processing must be carried out. The information superposition function of GIS technology is used to superimpose the thematic maps of control factors, and the information storage layers of each relevant factor are combined into one information storage layer to form the superimposed units containing all relevant factor information. Then, the constant weight of each evaluation factor is determined according to the analytic hierarchy process. On this basis, Matlab software is used to calculate the coal floor water inrush variable weight vulnerability evaluation model (formula (2)), and the weight calculation program 
TABLE 2: Comparison of typical unit evaluation results.

\begin{tabular}{lccccc}
\hline $\begin{array}{l}\text { Controlling } \\
\text { factors }\end{array}$ & $\begin{array}{c}\text { Normalized } \\
\text { value }\end{array}$ & $\begin{array}{c}\text { Constant } \\
\text { weight }\end{array}$ & $\begin{array}{c}\text { Variable } \\
\text { weight }\end{array}$ & $\begin{array}{c}\text { Constant weight evaluation } \\
\text { value }\end{array}$ & $\begin{array}{c}\text { Variable weight evaluation } \\
\text { value }\end{array}$ \\
\hline WALA & 0.196 & 0.1478 & 0.1121 & 0.0290 & 0.0220 \\
RQD & 0.483 & 0.0564 & 0.0565 & 0.0272 & 0.0273 \\
WPLA & 0.286 & 0.2956 & 0.2670 & 0.0845 & 0.0764 \\
TBRFZM & 0.325 & 0.1292 & 0.1290 & 0.0420 & 0.0419 \\
DFF & 1.000 & 0.1128 & 0.1763 & 0.1128 & 0.1763 \\
ETEA & 0.367 & 0.2582 & 0.2591 & 0.0948 & 0.0951 \\
Total value & & 1 & 1 & 0.3903 & 0.4389 \\
\hline
\end{tabular}

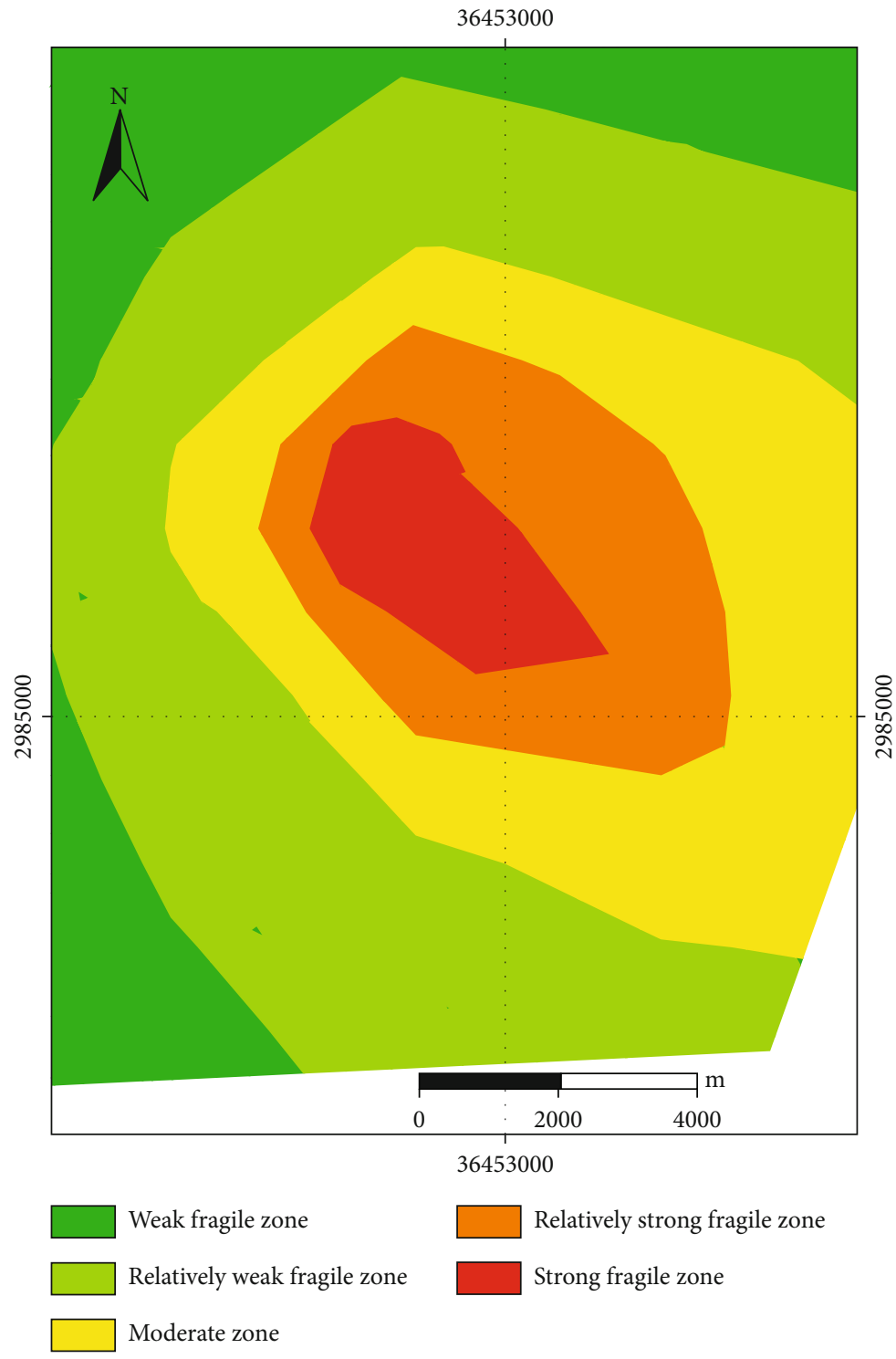

Figure 6: Partial enlarged map based on VWM.

can be obtained from Supplementary Materials. Finally, the water inrush vulnerability evaluation index of all superimposed units is obtained. Then, the natural break classification method in GIS software is used to classify, and finally, a floor water risk evaluation partition map is formed (Figure 4). For comparative analysis, we also made a partition map based on constant weights (Figure 5). The weights were obtained using the AHP, which was proposed by Saaty [32]. This method 


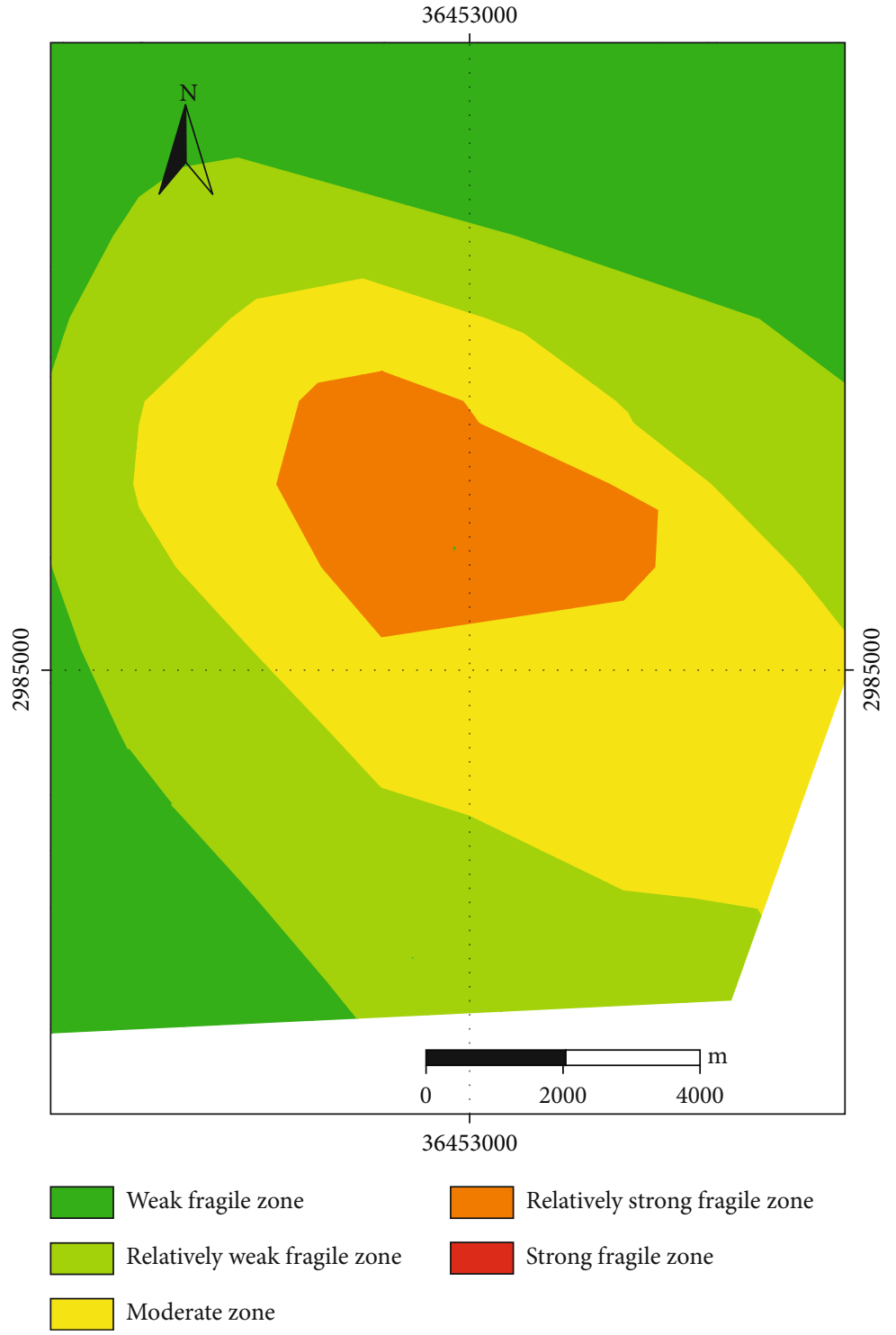

Figure 7: Partial enlarged map based on CWM.

obtains the factor weight by calculating the maximum eigenvalue of the judgment matrix and the eigenvectors. The constant weight calculation results are shown in Table 2.

\section{Evaluation Effect Analysis}

5.1. Comparison of Evaluation Maps. From the evaluation results (Figure 4), the fragile region areas are mainly distributed in the northern, central, and southeastern parts of the mining area. The main reason is that the WALA is rich and the WPLA is large in the northern mining area. The RQDA is poor, and the crack is very developed in the middle of the mining area. The ETEA is very thin in the southeastern mining area. The overall trend of the evaluation results of the two models is basically consistent, and the location of each fragile region is roughly the same, but the risk degree and scope of local have a difference; by the local amplification maps of Figures 6 and 7, it can be seen that the central position evaluation result of this region is the red fragile region under the
VWM. And under the CWM, the corresponding position evaluation result is the orange fragile area. The main reason for the difference is the uplift of limestone in the Maokou Formation in this area, and its aquiclude is very thin. The ETEA is much smaller than the surrounding area. The conventional CWM cannot reflect the sudden change of the ETEA in this area by adjusting the weight value. But in the process of variable weight evaluation, the weight of ETEA in this area is increased from the constant value of 0.2582 up to $0.326 \sim 0.336$. Therefore, the control effect of ETEA on water inrush is effectively highlighted. Compared with the traditional CWM, the evaluation results are more in line with the law of mine floor water inrush evaluation, which can better describe the control effect of key influencing factors on water inrush, and the evaluation results are more accurate.

5.2. Comparison of Evaluation Results of the Typical Unit. A typical evaluation unit in the research area is selected, and a 


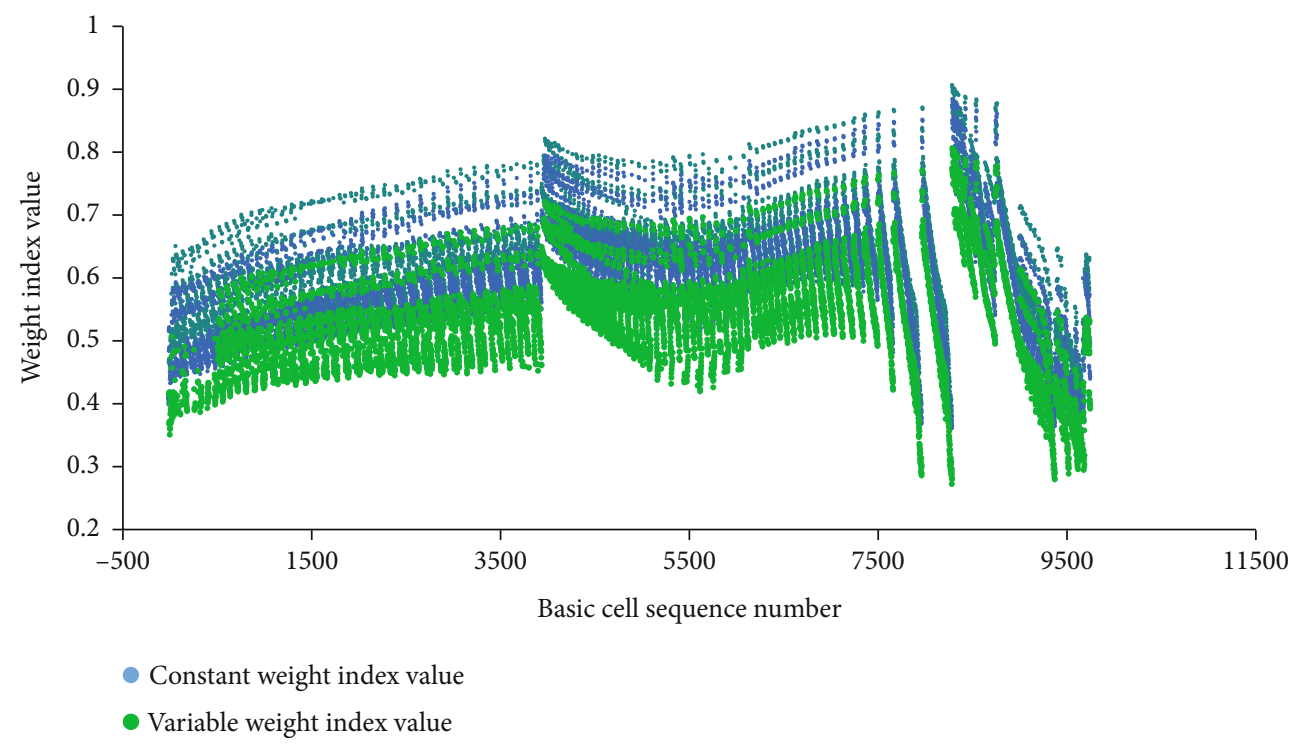

Figure 8: Comparison of the range of comprehensive evaluation values.

comprehensive evaluation value is calculated by using two methods of VWM and CWM (Table 2).

From Table 2, it can be clearly seen that the normalized value of the DFF of the evaluation unit is extremely large, and the value is 1 , which means that there is a geological structure at the location, and it is easy to induce a water inrush disaster. Compared with other factors, the DFF plays a stronger control role in water inrush. However, in the evaluation process of the CWM, the risk of these two factors was neutralized by the other five factors, resulting in the risk comprehensive evaluation value being reduced to 0.3903 . And by using the VWM for risk evaluation, according to the magnitude of the state value of control factors, VWM redistribute the weight of the control factors and increase the weight value of the DFF; the weight value increased from 0.1128 to 0.1763 , so that the risk comprehensive evaluation value increased to 0.4389 , which effectively prevents the key control factor of water inrush from being neutralized by other factors. Therefore, compared with the CWM, the evaluation process of the VWM is more in line with the actual geological conditions of the mining area, and the risk evaluation results are more accurate.

\subsection{Comparison of the Range of Comprehensive Evaluation} Values. For each evaluation superimposed unit in the study area, both two evaluation methods of the CWM and the VWM are used to calculate the risk index of water inrush. From the final calculation results, the risk index range of the CWM is $0.3456554 \sim 0.8890497$ and the risk index range of VWM is 0.314419 0.925728. The risk index distribution ranges of all evaluation units are shown in Figure 8. It can be seen that the risk index range of the VWM is larger than the CWM, and the dispersion is better. For the GIS-based multisource information fusion risk evaluation method of coal seam floor water inrush, a larger value range and a better dispersion mean that it is easier to determine the critical thresholds of different risk zones.

\section{Conclusion}

The coal seam floor water inrush evaluation technology based on GIS combined with linear or nonlinear mathematical theory is the current research hotspot, and the CWM is currently widely used. In order to overcome the shortcomings of the traditional evaluation method, the variable weight theory is introduced into the field of risk evaluation of water inrush from coal floor and puts forward the variable weight evaluation idea of water inrush. The VWM can overcome the defect that the weight value of the traditional evaluation model remains unchanged and can consider the effect of state value change of the influencing factors on the water inrush, especially the state value mutation on the water inrush, which can effectively improve the evaluation accuracy of water inrush based on multisource information fusion technology. In addition, the CWM is greatly affected by human factors in the weight determination process. The VWM realizes the weight change based on the constant weight, which will also be affected by certain human factors, but the weight change is determined according to the objective difference of the factor state value, which can effectively reduce the influence of human factors.

Combined with the example of the water inrush evaluation project of the coal floor in Weng'an Coal Mine, the differences in evaluation effects between VWM and CWM are compared from three aspects: evaluation map, typical unit, and comprehensive evaluation values. It is demonstrated that the VWM can better reflect the control effect of mine hydrogeological condition mutations on water inrush; the evaluation process and evaluation results are more consistent with the formation mechanism of coal floor water inrush.

The current VWM still has defects such as the lack of a versatile method of parameter determination, the evaluation process will be disturbed by human factors, and the research on the change law of the weight value under the condition that the state values of different factors are combined with 
each other is not deep. In the follow-up research work, it is necessary to continue to improve the variable weight evaluation theory of water inrush from coal floor, reduce the interference of human factors on the evaluation process, and explore a VWM that is more consistent with the evaluation characteristics of water inrush from coal floor.

\section{Data Availability}

All data included in this study are available upon request by contact with the corresponding author.

\section{Conflicts of Interest}

The authors declare that they have no conflicts of interest.

\section{Acknowledgments}

This research was financially supported by the National Natural Science Foundation (41702270), Guizhou Science and Technology Department Project (Qian Ke He Ji Chu [2019]1413, Qian Ke He Zhi Cheng [2020]4Y048, and Qian Ke He Zhi Cheng [2020]4Y007 and [2017]5788), and Department of Education of Guizhou Province ([2018]113).

\section{Supplementary Materials}

Figure S1: the thematic map of WALA. Figure S2: the thematic map of RQD. Figure S3: the thematic map of TBRBZU. Figure S4: the thematic map of ETEA. Figure S5: the thematic map of DFF. And factor weight calculation program. (Supplementary Materials)

\section{References}

[1] C. F. Santos and Z. T. Bieniawski, "Floor design in underground coalmines," Rock Mechanics and Rock Engineering, vol. 22, no. 4, pp. 249-271, 1967.

[2] S. K. Chaulya, "Water resource development study for a mining region," Water Resources Management, vol. 17, no. 4, pp. 297-316, 2003.

[3] J. C. Murphy, G. M. Hornberger, and R. G. Liddle, "Concentration-discharge relationships in the coal mined region of the New River basin and Indian Fork sub-basin, Tennessee, USA," Hydrological Processes, vol. 28, no. 3, pp. 718-728, 2014.

[4] K. F. Fan, W. P. Li, Q. Q. Wang et al., "Formation mechanism and prediction method of water inrush from separated layers within coal seam mining: a case study in the Shilawusu mining area, China," Engineering Failure Analysis, vol. 103, pp. 158172, 2019.

[5] B. Li, Q. Wu, X. Q. Duan, and M. Y. Chen, "Risk analysis model of water inrush through the seam floor based on set pair analysis," Mine Water and the Environment, vol. 37, no. 4, pp. 281-287, 2018.

[6] Engineering Geological Handbook Editorial Board, Engineering Geological Handbook, China Architecture \& Building Press, Beijing, 1992.

[7] E. T. Guan, "Water outburst coefficient and mine water disaster prevention and control," Coal Engineering, vol. 47, no. 1, pp. 46-48, 2011.
[8] L. M. Fan, L. Q. Ma, Y. H. Yu, S. K. Wang, and Y. J. Xu, "Water-conserving mining influencing factors identification and weight determination in northwest China," International Journal of Coal Science \& Technology, vol. 6, no. 1, pp. 95$101,2019$.

[9] V. F. Bense, E. H. van den Berg, and R. T. van Balen, "Deformation mechanisms and hydraulic properties of fault zones in unconsolidated sediments; the Roer Valley Rift System, The Netherlands," Hydrogeology Journal, vol. 11, no. 3, pp. 319-332, 2003.

[10] C. Drover, E. Villaescusa, and I. Onederra, "Face destressing blast design for hard rock tunnelling at great depth," Tunnelling and Underground Space Technology, vol. 80, pp. 257268, 2018.

[11] D. L. Hughson and A. Gutjahr, "Effect of conditioning randomly heterogeneous transmissivity on temporal hydraulic head measurements in transient two-dimensional aquifer flow," Stochastic Hydrology and Hydraulics, vol. 12, no. 3, pp. 155-170, 1998.

[12] B. Li, Q. Wu, and Z. J. Liu, "Identification of mine water inrush source based on PCA-FDA: Xiandewang coal mine case," Geofluids, vol. 2020, 8 pages, 2020.

[13] G. Dai, X. Xue, K. Xu, L. Dong, and C. Niu, “A GIS-based method of risk assessment on no. 11 coal-floor water inrush from Ordovician limestone in Hancheng mining area, China," Arabian Journal of Geosciences, vol. 11, no. 22, p. 714, 2018.

[14] Q. Wu, H. Xu, and W. Pang, "GIS and ANN coupling model: an innovative approach to evaluate vulnerability of karst water inrush in coalmines of north China," Environmental Geology, vol. 54, no. 5, pp. 937-943, 2008.

[15] Y. B. Hu, W. P. Li, Q. Q. Wang, S. L. Liu, and Z. K. Wang, "Evaluation of water inrush risk from coal seam floors with an AHP-EWM algorithm and GIS," Environmental Earth Sciences, vol. 78, no. 10, p. 290, 2019.

[16] S. L. Liu, W. T. Liu, Z. Huo, and W. C. Song, "Early warning information evolution characteristics of water inrush from floor in underground coal mining," Arabian Journal of Geosciences, vol. 12, no. 2, p. 30, 2019.

[17] L. W. Chen, X. Q. Feng, D. Q. Xu, W. Zeng, and Z. Y. Zheng, "Prediction of water inrush areas under an unconsolidated, confined aquifer: the application of multi-information superposition based on GIS and AHP in the Qidong coal mine, China," Mine Water and the Environment, vol. 37, no. 4, pp. 786-795, 2018.

[18] Z. Ruan, C. P. Li, A. X. Wu, and Y. Wang, "A new risk assessment model for underground mine water inrush based on AHP and D-S evidence theory," Mine Water and the Environment, vol. 38, no. 3, pp. 488-496, 2019.

[19] Z. K. Zhu, Z. M. Xu, Y. J. Sun, and X. L. Huang, "Research on the risk evaluation methods of water inrush from coal floor based on dimensionless multi-source information fusion technique," Journal of Mining \& Safety Engineering, vol. 30, no. 6, pp. 911-916, 2013.

[20] Q. Wu and M. Wang, "Characterization of water bursting and discharge into underground mines with multilayered groundwater flow systems in the North China coal basin," Hydrogeology Journal, vol. 14, no. 6, pp. 882-893, 2006.

[21] H. Chen, H. Qi, R. Y. Long, and M. L. Zhang, "Research on 10 -year tendency of China coal mine accidents and the characteristics of human factors," Safety Science, vol. 50, no. 4, pp. 745-750, 2012. 
[22] Q. Wu, B. Li, and Y. L. Chen, "Vulnerability assessment of groundwater inrush from underlying aquifers based on variable weight model and its application," Water Resources Management, vol. 30, no. 10, pp. 3331-3345, 2016.

[23] B. Li, X. Q. Wang, Z. J. Liu, and T. Li, "Study on multi-field catastrophe evolution laws of water inrush from concealed karst cave in roadway excavation: a case of Jiyuan coal mine," Geomatics, Natural Hazards and Risk, vol. 12, no. 1, pp. 222243, 2021.

[24] Y. F. Zeng, Research on Risk Evaluation Methods of Groundwater Bursting from Aquifers Underlying Coal Seams and Applications to Coalfields of North China, Springer Nature, 2018.

[25] Q. Wu, Y. Z. Liu, D. H. Liu, and W. F. Zhou, "Prediction of floor water inrush: the application of GIS-based AHP vulnerable index method to Donghuantuo Coal Mine, China," Rock Mechanics and Rock Engineering, vol. 44, no. 5, pp. 591-600, 2011.

[26] D. Ma, H. B. Bai, X. X. Miao, H. Pu, B. Y. Jiang, and Z. Q. Chen, "Compaction and seepage properties of crushed limestone particle mixture: an experimental investigation for Ordovician karst collapse pillar groundwater inrush," Environmental Earth Sciences, vol. 75, no. 1, pp. 1-14, 2016.

[27] H. X. Li, "Factor spaces and mathematical frame of knowledge representation (VII)-variable weights analysis," Fuzzy Systems \& Mathematics, vol. 9, no. 3, pp. 1-9, 1995.

[28] H. X. Li, "Factor spaces and mathematical frame of knowledge representation-feedback extension of a concept and coincidence of factors," Journal of Systems Engineering, vol. 11, no. 4, pp. 7-16, 1996.

[29] W. Q. Liu, "Balanced function and its application for variable weight synthesizing," Systems Engineering-Theory \& Practice, vol. 17, no. 4, pp. 58-64, 1997.

[30] D. Q. Li and H. X. Li, "The properties and constructions of state variable weight vectors," Journal of Beijing Normal University (Natural Science), vol. 38, no. 4, pp. 455-461, 2002.

[31] Q. F. Cai and H. X. Li, "Balance degree and variable weight," Systems Engineering-Theory \& Practice, vol. 21, no. 10, pp. 83-87, 2001.

[32] T. L. Saaty, "A scaling method for priorities in hierarchical structures," Journal of Mathematical Psychology, vol. 15, no. 3, pp. 234-281, 1977. 